\title{
Photoemission study of the copper/poly(ethylene terephthalate) interface
}

\author{
M. Chtaib, * J. Ghijsen, J. J. Pireaux, and R. Caudano \\ Facultés Universitaires Notre-Dame de la Paix, Laboratoire Interdisciplinaire de Spectroscopie Electronique, \\ rue de Bruxelles 61, B-5000 Namur, Belgium \\ R. L. Johnson \\ II. Institut für Experimentalphysik, Universität Hamburg, Luruper Chaussee 149, D-2000 Hamburg 50, Federal Republic of Germany
}

\author{
E. Ortí ${ }^{\dagger}$ and J. L. Brédas
}

Université de Mons-Hainaut, Avenue Maistriau, B-7000 Mons, Belgium

(Received 13 December 1990; revised manuscript received 20 May 1991)

\begin{abstract}
The metallization of poly(ethylene terephthalate) (PET) by copper has been studied by photoelectron spectroscopy ( $x$-ray and vacuum ultraviolet). The results are interpreted in the light of a valenceeffective-Hamiltonian band-structure calculation on the PET polymeric chain and by comparison with earlier work on copper oxides. The theoretical valence-band density of states is in very good agreement with the photoelectron spectra of PET and allows us to present a detailed interpretation of the valence electronic structure of PET. Upon metallization, we find that, for low coverages $\left(<5 \times 10^{14} \mathrm{Cu}\right.$ atoms $/ \mathrm{cm}^{2}$ ) copper binds preferentially to the oxygen from the carbonyl $(-\mathrm{C}=\mathrm{O})$ and the ether ($\mathrm{C}-\mathrm{O}-$ ) groups of the PET. At coverages near $7.5 \times 10^{14} \mathrm{Cu}$ atoms $/ \mathrm{cm}^{2}$, the additional copper remains metallic and gives rise to a three-dimensional islandlike growth mode. The low reactivity towards PET stands in sharp contrast to the case of other transition metals, like Ti and $\mathrm{Cr}$.
\end{abstract}

\section{INTRODUCTION}

Metallized polymers are used in a wide variety of applications ranging from integrated circuits, or data storage and recording media, ${ }^{1-3}$ to packaging materials. The chemical nature of the interface between the metal and polymer has been investigated by many research groups over the past decade. Using an array of surface analysis techniques, such as x-ray photoemission spectroscopy (XPS) and ultraviolet photoemission spectroscopy (UPS), high-resolution electron-energy-loss spectroscopy (HREELS), and secondary-ion-mass spectroscopy, it has been possible to elucidate some of the reaction mechanisms involved in the formation of the interfaces of $\mathrm{Cr}$, $\mathrm{Ti}$, or Al with pyromellitic dianhydride-oxydianiline polyimide (PMDA-ODA) ${ }^{4-8}$

In the late 1970s, Burkstrand showed, using XPS, that metal atoms $(\mathrm{Cu}, \mathrm{Cr}$, and $\mathrm{Ni}$ ) interact with the oxygenated functionality of polyvinyl alcohol and lead to the formation of a metal-oxygen-polymer complex at the interface. ${ }^{9}$ HREELS studies of the metal-polyimide couple indicates that at low coverage, metals interact with the carbonyl stretching band while higher coverages cause bond breakage. ${ }^{10-12}$ There is still no consensus on detailed models of $\mathrm{Cr}$ and $\mathrm{Cu}$ metallization of polyimide. Jordan et al. ${ }^{13}$ have suggested that the initial growth of $\mathrm{Cr}$ occurs as a consequence of its bonding to carbonyl groups, followed by the formation of metal carbide species for high metal coverages. On the other hand, Haight et al ${ }^{14}$ reported that $\mathrm{Cr}$ reacts preferentially with the PMDA part of the polyimide (PI) and induces the formation of a complex between $\mathrm{Cr}$ and the $\pi$-ring structure of the PMDA. Recently, Kowalczyk and JordanSweet ${ }^{15}$ studied "inverted" interfaces in the sense that both the monomers of PMDA and ODA that constitute the PI were molecularly deposited on $\mathrm{Cu}, \mathrm{Cr}$, and $\mathrm{Ag}$ substrates. They concluded that the interface formation occurred via an acid-base interaction between the metal and the polymer.

The copper-polymer interface is important for applications in microelectronic devices which use polymer dielectric films between copper tracks. Our concern here is to study the early stage of copper growth on poly(ethylene terephthalate) (PET). This polyester has a monomeric unit cell (Fig. 1) which contains one benzene ring, two oxygen atoms on a carbonyl group $(-\mathrm{C}=\mathrm{O})$, and two oxygen atoms in ether (-C-O-) configurations. The PET polymer chains are terminated by (-OH) groups. By comparison with previously reported results ${ }^{16-20}$ on the $\mathrm{Cu} / \mathrm{PI}$ interface, one could expect $\mathrm{Cu}$ to have a similar reactivity with PET and adhere weakly in contrast to other metals like $\mathrm{Cr}$ or $\mathrm{Ti}$.

We have used synchrotron radiation (SR) photoemission to follow the changes that occur in the valence-band structures of PET during copper deposition. XPS measurements on the same system $(\mathrm{Cu} / \mathrm{PET})$ allowed us to determine the growth mode of $\mathrm{Cu}$ and its reactivity on PET. We have performed band-structure and densityof-states (DOS) calculations to understand the electronic and spectral features in the valence region of the photoemission spectra of PET. This information will facilitate the interpretation of the electronic-structure changes induced by the formation of the Cu/PET interface. The theoretical approach employed is the valence-effectiveHamiltonian (VEH) quantum-chemical technique, which has been shown to provide an accurate picture of the valence electronic structure for a wide variety of polymers. ${ }^{21-26}$ In relation to the present work, the excellent 


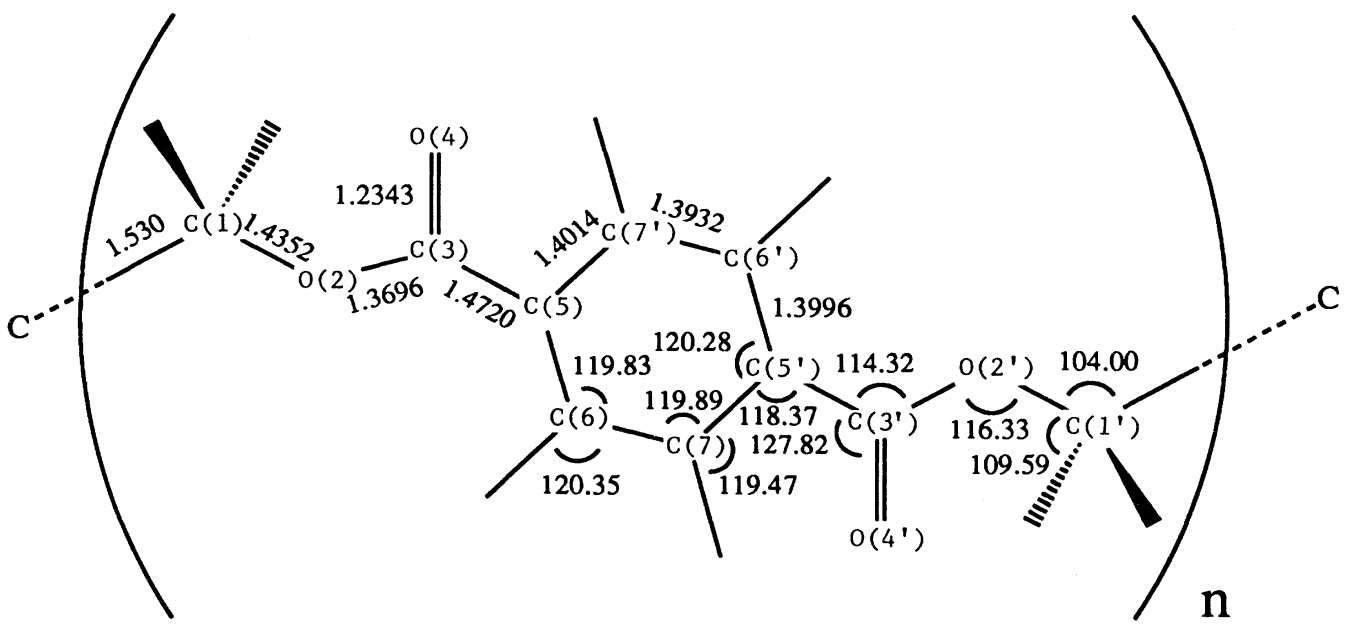

FIG. 1. Molecular and geometric structure of the unit cell of PET. Bond lengths are in angstroms and bond angles in degrees. The unit cell exhibits a $C_{2 h}$ symmetry. All $\mathrm{H}-\mathrm{C}$ bond lengths are about $1.10 \AA$.

agreement found between VEH results and UPS and XPS data from the related polymeric systems polyimide ${ }^{25}$ and poly (ether ether ketone) (PEEK) (Ref. 26) should be mentioned. The approach presented here is discussed in light of other metal-polymer interfaces reported in the literature.

\section{EXPERIMENT}

\section{A. Analytical tools}

The photoemission experiments in the vacuum ultraviolet domain were performed at the FLIPPER II monochromator at the Hamburger Synchrotronstrahlungslabor on the DORIS II storage ring located at DESY (Hamburg, Germany). The electrons were analyzed using a double-pass cylindrical mirror analyzer and the overall resolution was better than $0.3 \mathrm{eV}$. More details of the experimental setup have been published elsewhere. ${ }^{27}$ The XPS core-level studies were performed with an X-probe 206 ESCA spectrometer (Surface Science Instruments). The spectra were recorded using a monochromatized Al $K \alpha$ source $(1486.6 \mathrm{eV})$ and the $\mathrm{x}$-ray spot size was set to $600 \mu \mathrm{m}$ diameter in order to achieve a good data collection rate. The resolution on the main $\mathrm{C} 1 \mathrm{~s}$ carbon peak of PET was about $1.0 \mathrm{eV}$. For the XPS measurement, the binding energies were referred to the "neutral" carbon (CH) position at $284.6 \mathrm{eV}$. This energy scale is compatible with the binding energies derived from the Fermi level of copper metallized samples. No radiation damage to the polymer sample was observed during the photoemission study. Whereas the charge effects were small or even negligible for the SR measurements, an electron flood gun had to be used during the XPS measurements.

\section{B. Materials}

For both synchrotron photoemission and for XPS, the substrates used were thin PET films cast out of a solution in trifluoroacetic acid (TFA: $4 \mathrm{mg} / \mathrm{l}$ ) and spun (4000 revolutions per minute) on a $\mathrm{Au}(110)$ crystal. After synthesis the films were outgassed in vacuum for more than $48 \mathrm{~h}$ before analysis. We have also used a bulk PET substrate (du Pont, Mylar ${ }^{\circledR}$ ). There were no major differences between the spectra obtained from either substrate. However, the spin-coated PET seemed to show a better charge stability during the XPS measurements. High-purity copper $(99.999 \%)$ was used for the evaporations.

\section{Metallic layers growth on PET}

Cu was evaporated in situ in the submonolayer regime from a Knudsen effusion cell, previously outgassed for a few days. The evaporation rate was measured with a quartz microbalance. A very low evaporation rate (less than $1 \AA / \mathrm{min}$ ) could be maintained without any modification of the base pressure (about $10^{-10}$ Torr). The metallic coverages are expressed hereafter in number of $\mathrm{Cu}$ atoms per $\mathrm{cm}^{2}$. In the $\mathrm{Cu}(001)$ plane the $\mathrm{Cu}-\mathrm{Cu}$ nearest-neighbor distance is $2.55 \AA ;^{28}$ this corresponds to $1.5 \times 10^{15} \mathrm{Cu}$ atoms $/ \mathrm{cm}^{2}$. It is easy to derive also that a $\mathrm{Cu}$ thickness of $1 \AA$ will correspond on a flat surface to a coverage around $5.9 \times 10^{14} \mathrm{Cu}$ atoms $/ \mathrm{cm}^{2}$. According to PET crystallographic data $^{29}$ and assuming that the PET monomer units (Fig. 1) are mostly lying flat at the surface, we estimate the number of monomers per $\mathrm{cm}^{2}$ to be of the order of $1.8 \times 10^{14}$. That is to say that a coverage of one $\mathrm{Cu}$ atom per PET unit cell could be achieved by a $\mathrm{Cu}$ thickness of $0.31 \AA$.

\section{THEORY}

\section{A. Methodology}

The electronic band-structure calculations presented here have been performed using the nonempirical VEH technique. This method was developed for molecular cal- 
culations by Nicolas and Durand ${ }^{30}$ and extended for the treatment of stereoregular polymeric systems by André et $a l .^{31}$ The VEH method is based on the use of an effective Fock Hamiltonian $F_{\text {eff }}$, which combines a kinetic term and a summation over atomic potentials. All the parameters entering the atomic potentials are optimized on model molecules in order to minimize the difference between $F_{\text {eff }}$ and the Fock Hamiltonian built from Hartree-Fock $a b$ initio double- $\zeta$ calculations. In this way, the VEH method is completely nonempirical and yields one-electron energy levels of $a b$ initio double- $\zeta$ quality. The VEH atomic potentials used in this work are those previously optimized for hydrogen, carbon, and oxygen. $^{32,33}$

From the band structure, the densities of valence states (DOVS) are calculated following the methodology of Delhalle and Delhalle. ${ }^{34}$ To obtain a theoretical simulation of the XPS spectrum, it is necessary to include the effect of relative photoionization intensities of the crystal orbitals in the DOVS curve. To do so, we use the Gelius model, ${ }^{35}$ as extended to polymers. ${ }^{36}$ This model relates the photoionization intensity $I_{n}$ of the $n$th one-electron level to (i) the Mulliken gross atomic populations and (ii) the experimental relative photoionization cross sections $\sigma_{p}$ of the atomic orbitals $\chi_{p}$ used in the linear combination of atomic orbitals (LCAO) expansion:

$$
I_{n}(k) \alpha \sum_{p} C_{n p}(k)\left(\sum_{q} S_{p q}(k) C_{n q}(k)\right) \sigma_{p} .
$$

In this expression, $C_{n p}$ and $C_{n q}$ denote the coefficients of the LCAO expansion and $S_{p q}$ is the overlap integral between $\chi_{p}$ and $\chi_{q}$. The $p$ and $q$ summations run over the set of atomic orbitals. The values used for $\sigma_{p}$ are the following: ${ }^{35} \sigma(\mathrm{O}, 2 s)=1.4, \sigma(\mathrm{O}, 2 p)=1.4 / 8, \sigma(\mathrm{C}, 2 s)=1$, $\sigma(\mathrm{C}, 2 p)=\frac{1}{13}$, and $\sigma(\mathbf{H}, 1 s)=0 ; \sigma(\mathrm{C}, 2 s)$ is being taken as a reference.

In order to compare the calculated DOS curves to the experimental photoemission spectra (XPS or UPS), a three-step procedure is generally used ${ }^{22,24,25}$ and consists in the following.

(i) The convolution of the DOVS curves by a Gaussian function of adjustable full width at half maximum (FWHM). This is a way of introducing the static and dynamic disorder effects that exist in the solid state and cause a broadening of the photoemission linewidths with respect to the gas phase.

(ii) The application of a rigid shift of the DOVS curves towards lower binding energies in order to deal with the solid-state polarization energy due to interchain relaxation effects. This effect cannot be included $a$ priori in the band-structure calculations, which are performed on isolated chains.

(iii) The contraction of the theoretical energy scale in order to correct the too-wide valence band that HartreeFock $a b$ initio calculations and, therefore, VEH calculations provide. The contraction factor is easily obtained as the slope of a linear regression correlating the corresponding experimental and theoretical peak positions. It should be emphasized that a consistent value of about 1.3 for this contraction factor is found for all previous VEH studies. $^{21-26}$

\section{B. Geometry}

The geometrical parameters used to build up the unit cell of PET are displayed in Fig. 1; they are based on the geometry optimized on dimethylterephthalate using the Austin Model 1 semiempirical Hartree-Fock method. ${ }^{37}$ The calculated bond lengths are in good agreement with those experimentally reported for diethylterephthalate. ${ }^{38}$ However, they significantly differ from the $\mathrm{x}$-ray data on PET, ${ }^{29}$ which, for instance, provide $\mathrm{C}-\mathrm{C}$ bond lengths much too short (1.34-1.36 $\AA$ ) for benzene rings. The ester groups are optimized to remain in the plane of the benzene ring, in agreement with the experimental observations. ${ }^{29,38}$ As a result, the unit cell presents a $C_{2 h}$ point symmetry and a fully planar conformation has been adopted for the PET chain. It should be noted that the introduction of $60^{\circ}$ rotations around $\mathrm{C}(1)-\mathrm{C}\left(1^{\prime}\right)$ bonds (Fig. 1), which leads to a gauche conformation, induces no significant modification in the electronic band structure of PET.

\section{RESULTS AND DISCUSSION}

\section{A. Analysis of clean PET surface}

\section{By SR photoemission}

Energy distribution curves (EDC's) from a PET thin film and from a clean bulk PET samples are shown in Fig. 2. The overall shape of the curves is in good agreement with the XPS valence band and with the convoluted

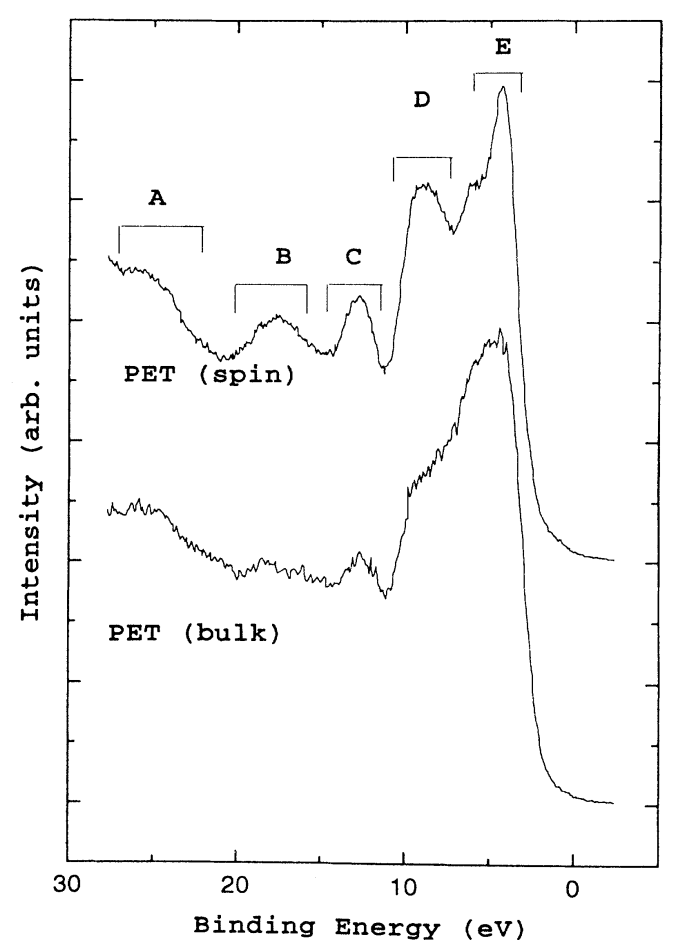

FIG. 2. EDC from (a) a PET thin film and (b) a clean bulk PET sample, recorded for a photon energy of $120 \mathrm{eV}$. 
DOVS theoretical curves (see below). The spectral features will be interpreted in detail following a discussion of the theoretical calculations.

\section{By $x$-ray photoelectron spectroscopy}

Valence levels. XPS is not the best way to probe the valence-band structure due to the low cross sections of the $\pi$ electrons in the valence orbitals. However, overnight accumulation ${ }^{39}$ on PET can give a reasonable valence-band spectrum. The XPS VB of Fig. 3 reveals the presence of structures similar to those already shown by SR photoemission in Fig. 2 .

Core levels. The C $1 s$ and $\mathrm{O} 1 s$ core-level spectra of pristine PET are presented in Fig. 4. The C $1 s$ signal exhibits three well-resolved peaks which can be assigned as follows: peak (1) is due to benzene carbons (this peak is set at a binding energy of $284.6 \mathrm{eV}$ ), peak (2) at $286.16 \mathrm{eV}$ is the contribution of the ether- $\mathrm{C}-\mathrm{O}$ groups, while peak (3) at higher binding energy $(288.6 \mathrm{eV})$ is attributed to $\mathrm{C}$ atoms involved in carbonyl bonds $(-\mathrm{C}=\mathrm{O}) .40,41$ The weak feature at about $290.5 \mathrm{eV}$ is due to electrons that have lost energy in a $\pi^{*} \leftarrow \pi$ shakeup process. The shakeup satellites correspond to electronic transitions in the presence of the core photohole. Their intensity and separation from the main peak have been related to the degree of electron delocalization (e.g., in the benzene ring). ${ }^{42}$ The $\mathrm{O} 1 \mathrm{~s}$ signal contains two peaks corresponding to the carbonyl oxygen $(\mathrm{O}=\mathrm{C}-)$ on the low binding-energy side and to the (--O-C- - ether group for the peak at higher binding energy. The carbon peaks are in $1: 1: 3$ intensity ratio and the oxygen peaks have equal intensities in agreement with the theoretical stoichiometry. We take this together with the VB spectra as an assessment of the PET surface cleanness.

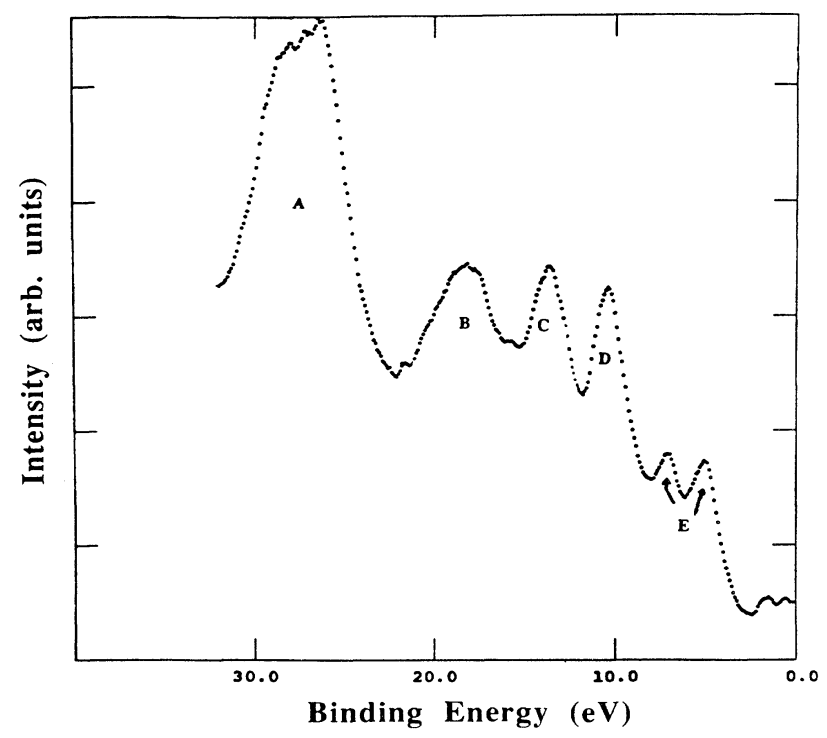

FIG. 3. XPS valence band of bulk PET.
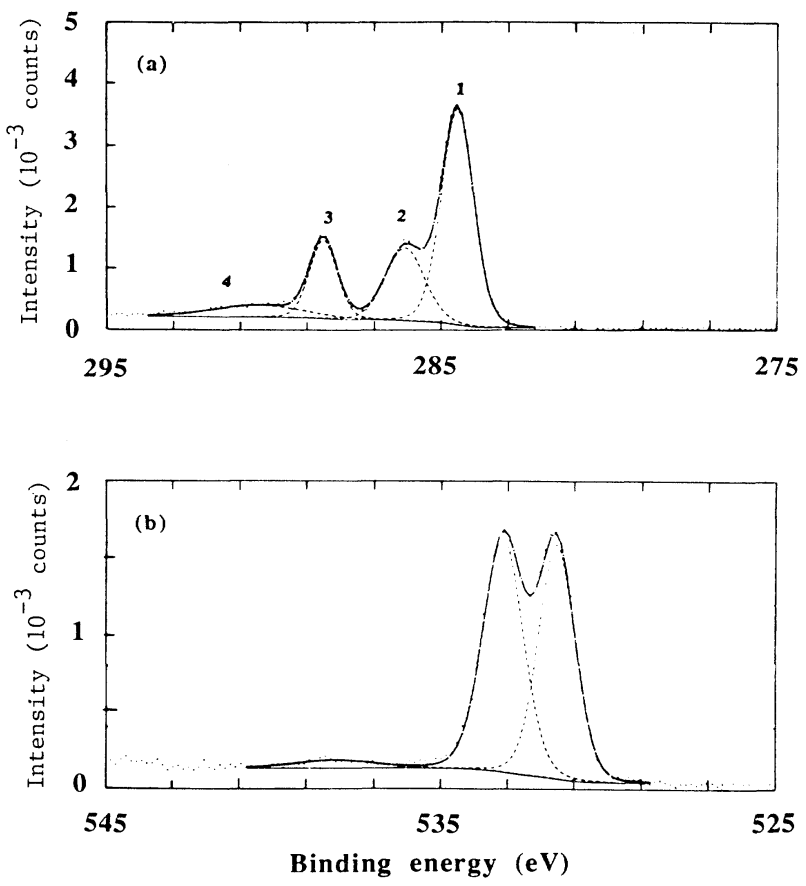

FIG. 4. (a) $\mathrm{C} 1 s$ and (b) O $1 s$ core levels of PET. The assignment of the different peaks is discussed in the text.

\section{By VEH band-structure calculations}

The VEH valence-band structure calculated for a fully planar PET chain is displayed in Fig. 5 together with the correlated DOVS curves. The valence-band structure contains 36 occupied bands which have been numbered starting from the bottom of the valence band. All of these bands show very small widths, the maximum dispersion $(1.10 \mathrm{eV})$ being found for band 9. This feature indicates that there is almost no effective electron delocalization along the whole polymer chain and that electronic states in PET are highly localized within single unit cells. The reason for this localization can be found in the presence of two saturated carbon and oxygen
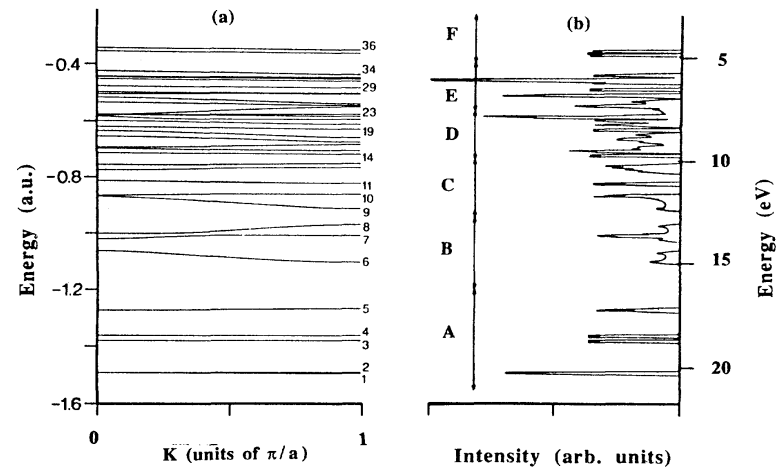

Intensity (arb. units)

FIG. 5. VEH (a) valence-band structure and (b) density of states for PET. Only the occupied bands are displayed. 
atoms separating the conjugated moieties. We now turn to a detailed analysis of the characteristics and atomic compositions of the bands, in order to assign precisely the origin of the peak structure in the DOVS curves.

Peak structure $A$ in Fig. 5 results from bands 1 to 5 . The first four bands are mainly built from oxygen $2 s$ atomic orbitals. These bands are split into two groups corresponding to the bonding (bands 1 and 2) and antibonding (bands 3 and 4) interactions of oxygen orbitals with the $2 s$ orbitals of the carbonyl $\mathrm{C}(3)$ and $\mathrm{C}\left(3^{\prime}\right)$ atoms, which give rise to peak $A_{1}$ and $A_{2}$, respectively. Peak $A_{3}$ originates in band 5, which comes from the totally bonding $1 a_{1 g}-\mathrm{C} 2 s$ orbital of benzene [see Table I of Ref. 24(b) for a detailed picture of the benzene molecular levels].

Peak structure $B$ corresponds to electronic states derived from the lower degenerate $1 e_{1 u}$ electronic level of benzene. The feature at higher binding energies results from the more dispersed band 6 with strong bonding interactions between $\mathrm{C}(3)$ and $\mathrm{C}\left(3^{\prime}\right) 2 s$ orbitals and the benzene ring. The peak at lower binding energies mostly originates in the $1 e_{1 u}$ level with no $2 s$ contribution from the paracarbons.

Peak structure $C$ contains three different features resulting from bands 9 and 10,11, and 12 and 13, respectively. While the first two peaks mainly result from benzene $1 e_{2 g}$ orbitals, the lower binding-energy peak derives from $\mathrm{O}(2)-\mathrm{C}(3)$ and $\mathrm{O}\left(2^{\prime}\right)-\mathrm{C}\left(3^{\prime}\right) \sigma$ bonds (band 12) and the $2 a_{1 \mathrm{~g}}$ level of benzene (band 13).

As many as 11 bands (14 to 24) are involved in the peak structure labeled $D$. The lowest of these correspond to $\mathrm{C}(1), \mathrm{C}\left(1^{\prime}\right)-\mathrm{H}$ bonds and bonds involving the ester group; they give rise to the two peaks lying at higher binding energies. Between these two peaks and the highintensity peak at lower binding energies, there are two peak structures of low intensity. The lowest intensity structure mostly derives from $\mathrm{O}(4)$ and $O\left(4^{\prime}\right)$ lone pairs (bands 16 and 17) and the benzene $1 b_{1 u}$ orbital, while the other structure originates in $\pi$ bonds delocalized over the ester groups (band 19) and benzene $\mathbf{C}-\mathrm{H}$ and $\mathrm{C}-\mathrm{C}$ bonds (bands 20 and 21). Finally, the high-intensity peak at lower binding energies results from bands 22 and 23, which are built from $\mathrm{C}-\mathrm{C}(1)-\mathrm{O}(2)$ and $\mathrm{C}-\mathrm{C}\left(1^{\prime}\right)-$ $\mathrm{O}\left(2^{\prime}\right) \sigma$ bonds and the strongly bonding $\mathrm{C}-\mathrm{H} 2 e_{1 u}$ orbital of benzene, respectively.

Peak structure $E$ involves three main peaks. The first peak has a relatively low intensity and mainly derives from $\mathrm{C}(3)-\mathrm{O}(4)$ and $\mathrm{C}\left(3^{\prime}\right)-\mathrm{O}\left(4^{\prime}\right) \pi$ bonds (bands 24 and 25). The middle peak results from bands 27 and 28 associated with $\mathrm{C}-\mathrm{H}$ bonds and oxygen lone pairs. The highest intensity peak contains bands 30 to 34 , mostly involving lone pairs from all the oxygen atoms. Finally, the uppermost two valence bands of PET, which derive directly from the degenerate $1 e_{1 g}$ electronic levels of benzene, give rise to peak structure $F$.

In order to compare with experimental data, a theoretical simulation of the photoemission spectra has been calculated for PET using the photoionization cross sections in the case of the XPS simulation. The resulting DOVS curves, convoluted by Gaussian line shapes and contract- ed by a factor of 1.26 as discussed above, are presented in Fig. 6 together with experimental SR photoemission and XPS data. A rigid shift to lower binding energies has been applied to the VEH spectra in order to align peak $F$ with the shoulder of the lowest binding-energy feature in the XPS spectrum. Bands in Fig. 6 are labeled in the same way as the peak structures discussed for Fig. 5(b). The binding energies and atomic composition of the most salient features of theoretical and experimental XPS spectra are summarized in Table $I$ to facilitate a detailed analysis of the correspondence between theory and experiment.
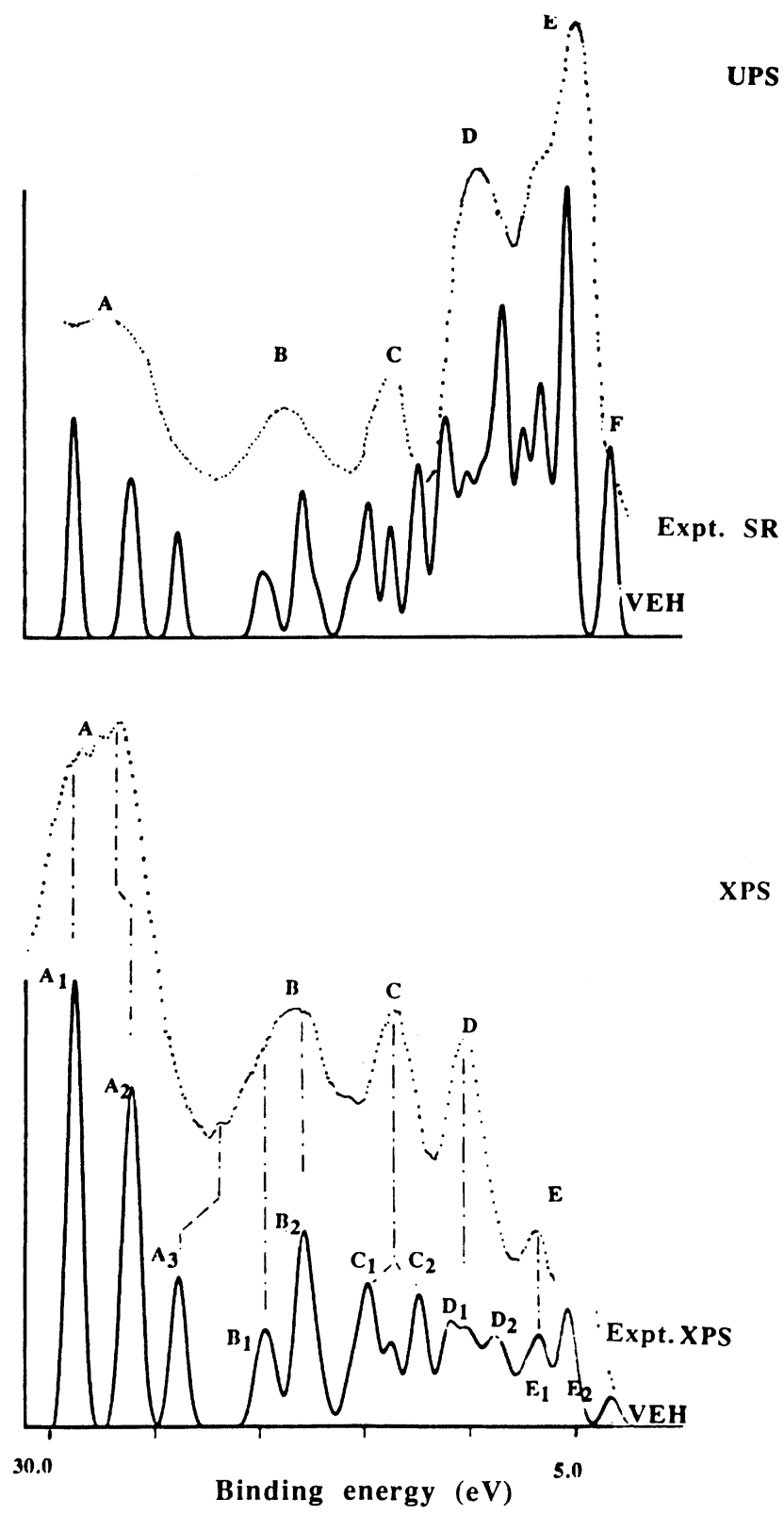

FIG. 6. VEH DOVS curves, convoluted by Gaussian line shapes of FWHM $0.7 \mathrm{eV}$ (UPS) and $1.0 \mathrm{eV}$ (XPS), shifted and contracted as discussed in the text, together with SR and XPS experimental data. 
TABLE I. Calculated (VEH) and measured (XPS) binding energies (eV) for the most important features in the valence band of PET. "sh" denotes a shoulder.

\begin{tabular}{|c|c|c|c|}
\hline Code $^{\mathrm{a}}$ & $\varepsilon_{i}^{\mathrm{b}}$ & $\varepsilon_{i}{ }^{\mathrm{c}}$ & XPS \\
\hline$A_{1}(\mathrm{O} 2 s$ binding $)$ & 40.65 & 28.12 & 28.10 \\
\hline$A_{2}$ (O $2 s$ antibonding) & 37.31 & 25.47 & 26.16 \\
\hline$A_{3}\left(1 a_{1 g}, \mathrm{C} 2 s\right)$ & 34.54 & 23.27 & $21.58 \mathrm{sh}$ \\
\hline$B_{1}\left[1 e_{1 u}+\mathrm{C}(3),\left(3^{\prime}\right), \mathrm{C} 2 s\right]$ & 29.60 & 19.34 & \\
\hline$B_{2}\left(1 e_{1 u}, \mathrm{C} 2 s\right)$ & 27.32 & 17.54 & 17.93 \\
\hline \multirow[t]{2}{*}{$C_{1}\left(1 e_{2 g}, \mathrm{C} 2 s\right)$} & 23.63 & 14.61 & \\
\hline & $22.31 \mathrm{sh}$ & 13.56 & 13.58 \\
\hline$C_{2}\left[\mathrm{O}(2),\left(2^{\prime}\right)-\mathrm{C}(3),\left(3^{\prime}\right), \sigma\right.$ bonds $]$ & 20.68 & 12.27 & \\
\hline $\begin{array}{l}D_{1}\left[\mathrm{C}(1),\left(1^{\prime}\right)-\mathrm{H} \text { and } \mathrm{COO} \pi \text { bonds }\right] \\
{\left[\mathrm{O}(4),\left(4^{\prime}\right) \text { lone pairs }\right.}\end{array}$ & 18.83 & 10.80 & \\
\hline plus $1 b_{1 u}$, C $\left.2 s-\mathrm{H}\right]$ & $18.00 \mathrm{sh}$ & 10.14 & 10.26 \\
\hline \multicolumn{4}{|l|}{$D_{2}\left[\mathrm{C}-\mathrm{C}(1),\left(1^{\prime}\right)-\mathrm{O}(2),\left(2^{\prime}\right)\right.$} \\
\hline plus $2 e_{1 u}$, C $\left.2 p-\mathrm{H}\right]$ & 16.29 & 8.79 & \\
\hline \multicolumn{4}{|l|}{$E_{1}\left[\mathrm{C}(3),\left(3^{\prime}\right)-\mathrm{O}(4),\left(4^{\prime}\right) \pi\right.$ bonds } \\
\hline plus $\mathrm{C}-\mathrm{H}$ bonds] & 13.78 & 6.79 & 6.94 \\
\hline$E_{2}$ (oxygen lone pairs) & 12.10 & 5.46 & 4.87 \\
\hline$F\left(1 e_{1 g}, \pi\right.$ C $\left.2 p\right)$ & 9.58 & 3.46 & $3.46 \mathrm{sh}$ \\
\hline
\end{tabular}

${ }^{a}$ Labels correspond to those used in Figs. 5 and 6. The main atomic contributions are indicated in parentheses according to Sec. III A 3. Contributions from the phenyl ring are denoted by the symmetry of the corresponding molecular orbitals of benzene.

${ }^{b} \mathrm{VEH}$ binding energies calculated for an isolated chain of PET.

${ }^{c}$ VEH binding energies after a contraction of 1.26 of the energy scale and a rigid shift of the valence band to match the first experimental feature at $3.46 \mathrm{eV}$.

As can be observed from Fig. 6 and Table I, the overall agreement between the theoretical and experimental spectra is good. Going from lower to higher binding energies, theoretical peak $F$ has been aligned with the small shoulder on the low binding-energy side of experimental peak $E_{2}$, as mentioned above. This assignment has been performed on the basis of $\mathrm{VEH}$ calculations on the related ethyl phenylacetate $\left(\mathrm{C}_{6} \mathrm{H}_{5} \mathrm{CH}_{2} \mathrm{COOCH}_{2} \mathrm{CH}_{3}\right)$ molecule. The $\mathrm{He}$ I gas-phase photoelectron spectrum reported for this molecule ${ }^{43}$ associates the first two ionization potentials found at 9.05 and $9.35 \mathrm{eV}$ to the $1 e_{1 g} \pi$ levels of the benzene moiety and those measured at 10.34 and $10.86 \mathrm{eV}$ to the lone pairs of the carbonyl and hydroxyl oxygens, respectively. The VEH results perfectly reproduce the energies and splitting of the features related to the $1 e_{1 g}$ levels of benzene (9.01 and $9.29 \mathrm{eV}$ ). However, VEH overestimates those corresponding to the oxygen lone pairs (10.92 and $11.30 \mathrm{eV}$ ) by about $0.6 \mathrm{eV}$. This is also the case for smaller ester compounds like methyl formiate $\left(\mathrm{HCOOCH}_{3}\right)$ or methyl acetate $\left(\mathrm{CH}_{3} \mathrm{COOCH}_{3}\right)$, for which VEH calculations overestimate the first ionization potential resulting from the carbonyl oxygen lone pairs by 0.9 and $1.2 \mathrm{eV}$, respectively. It thus comes as no surprise that the theoretical peak $E_{2}$ of PET, deriving from all the oxygen lone pairs, is calculated to be too high in binding energy $(5.46 \mathrm{eV})$; this peak has to be shifted to lower binding energy by $0.6 \mathrm{eV}$ as in the ethyl phenylacetate molecule. By doing so, this peak perfectly matches the experimental XPS peak $E_{2}$ at $4.87 \mathrm{eV}$; as a result theoretical band $F$, involving benzene $1 e_{1 g}$ elec- tronic states, becomes a shoulder of band $E_{2}$, as observed in the experimental XPS spectrum (Fig. 6).

The experimental XPS peak $E_{1}$ observed at $6.94 \mathrm{eV}$ is in excellent correlation with the theoretical peak $E_{1}$ calculated at $6.79 \mathrm{eV}$ and mainly coming from the $\mathrm{C}=\mathrm{O} \pi$ bonds. The photoemission band $D$ can be associated with the theoretical structure $D_{1}$, which mostly derives from $\mathbf{C}-\mathbf{H}$ bonds and oxygen atoms (see Table I). The experimental band $C$, measured at about $13.58 \mathrm{eV}$, does not correspond clearly to one band of the calculated spectra. We have correlated this band with theoretical peaks $C(1)$ and $\mathrm{C}(2)$ resulting from the benzene $1 e_{2 g}-\mathrm{C} 2 s$ levels and $\mathrm{O}(2)-\mathrm{C}(3) \sigma$ bonds, respectively, since the center of these two structures $(13.44 \mathrm{eV})$ corresponds almost exactly to the energy reported for the experimental band $(13.58 \mathrm{eV})$. Indeed the theoretical splitting of band $C$ has previously been observed for PEEK, ${ }^{26}$ which exhibits a molecular structure with features very similar to PET.

The broad experimental band $B$ perfectly correlates with the double-peak theoretical structure $B$ and can be envisioned as a C $2 s$ photoemission band. As discussed above, the main peak $B_{2}$ is localized within the phenyl rings of PET since it results from the benzene $1 e_{1 u}$ level with no contribution on the paracarbons connecting the chain. Indeed, peak $\boldsymbol{B}_{2}$ appears at an energy $(27.32 \mathrm{eV}$, before contraction and shift) almost equal to that observed for the $1 e_{1 u}$ levels of the benzene molecule $(27.14$ eV). ${ }^{24(b)}$ Band $B$ broadens on its high binding-energy side due to the interaction of the other benzene $1 e_{1 u}$ level with $\mathrm{C}(3)$ and $\mathrm{C}\left(3^{\prime}\right)$ atoms (peak $\left.B_{2}\right)$. 
Theoretical peak $A_{3}$ corresponds to the benzene $1 a_{1 g}-\mathrm{C} 2 s$ electronic state. As previously discussed, ${ }^{21,24}$ the VEH method calculates this level to lie about $2 \mathrm{eV}$ too high in binding energy. In this way, peak $A_{3}$ should be shifted to lower binding energies and can be correlated with the small feature observed between the photoemission bands $A$ and $B$ in the XPS spectrum (Fig. 6). Finally, the highest-intensity band $A$ clearly results from $\mathrm{O} 2 s$ electronic levels, giving rise to theoretical peaks $A_{1}$ and $A_{2}$. As for PET, the $A_{2}$ peak is calculated to lie too low in energy for small ester-type compounds.

\section{B. Cu/PET interface growth}

\section{Analysis by vuv photoemission}

After recording a reference EDC from clean PET, Cu was evaporated stepwise with dose units of about $1.6 \times 10^{14} \mathrm{Cu}$ atoms $/ \mathrm{cm}^{2}$. This corresponds to the deposition of roughly one $\mathrm{Cu}$ atom onto one PET unit cell (see Sec. II C), provided a unitary sticking coefficient is assumed. This value is further supported by the form of the dependence of the $[\mathrm{O}] /[\mathrm{C}]$ ratio upon coverage. For thicknesses above $1 \AA\left(\approx 5.8 \times 10^{14} \mathrm{Cu}\right.$ atoms $\left./ \mathrm{cm}^{2}\right)$ on the sample, higher doses were used up to a total of $6.0 \times 10^{15} \mathrm{Cu}$ atoms $/ \mathrm{cm}^{2}$. Figure 7 presents the valence band obtained using $70-\mathrm{eV}$ photon energy during the copper deposition. The peak assignments for the highest $\mathrm{Cu}$ coverages (curve $f$ in Fig. 7) are listed as follows.

When the $\mathrm{Cu}$ coverage on PET increases, the $\mathrm{O} 2 \mathrm{~s}$ peaks decrease gradually in intensity without showing any shift in energy position. The band $(B)$ which originates from $\mathrm{C} 2 s$ levels of benzene carbon atoms is slightly perturbed, showing a small shift towards the Fermi edge side. With increasing $\mathrm{Cu}$ coverage several other peaks start to build up. At coverages as low as $4.2 \times 10^{14} \mathrm{Cu}$ atoms $/ \mathrm{cm}^{2}$, one observes the appearance of a feature at the Fermi edge indicating a metalliclike state at the interface. More evidence for the early appearance of the metallic state will be given later in Sec. IV B 2.

Furthermore, band $(C)$ shows increasing intensity accompanied by a shift in binding energy from 13.6 to 15 $\mathrm{eV}$. In fact, this band is a mixture of two unresolved contributions that we have attributed in accordance with the $\mathrm{VEH}$ calculation to $\sigma$ electrons of $\sigma_{\mathrm{C}-\mathrm{O}}$ and benzene $\sigma_{\mathrm{C}-\mathrm{C}}$ bonds (see Table I). With the $\sigma_{\mathrm{C}-\mathrm{O}}$ located at 12.3 $\mathrm{eV}$, an intensity decrease of this band with a constant or an increasing intensity of the $\sigma_{\mathrm{C}-\mathrm{C}}$ located at $14.6 \mathrm{eV}$ might appear as a downhill shift of the peak centroid. This shift might also be a genuine consequence of an (even though weak) electron charge transfer from $\mathrm{Cu}$ atoms to the $\mathrm{C}-\mathrm{O}$ group of the polymer. Indeed, in a recent paper on $\mathrm{O} 2 s$ levels, Ranke and $\mathrm{Kur}^{44}$ show that the $\mathrm{O} 2 s$ level in $\mathrm{O}(2)$ or CO can split into bonding $2 \sigma_{g}$ and antibonding $2 \sigma_{u}$ orbitals as a consequence of their partial mixture with other orbitals like $\mathrm{O} 2 p$ (or $\mathrm{C} 2 s$ in $\mathrm{CO}$ ). Although in the case of $\mathrm{Cu}^{\mathrm{II}}$ surrounded by oxygen an additional peak is expected around $16-17 \mathrm{eV}$ below the Fermi level, it is in any case very weak and unlikely to be responsible for the changes observed in peak $(C) .{ }^{45}$

In the bands labeled $D$ to $F$, several changes are to be

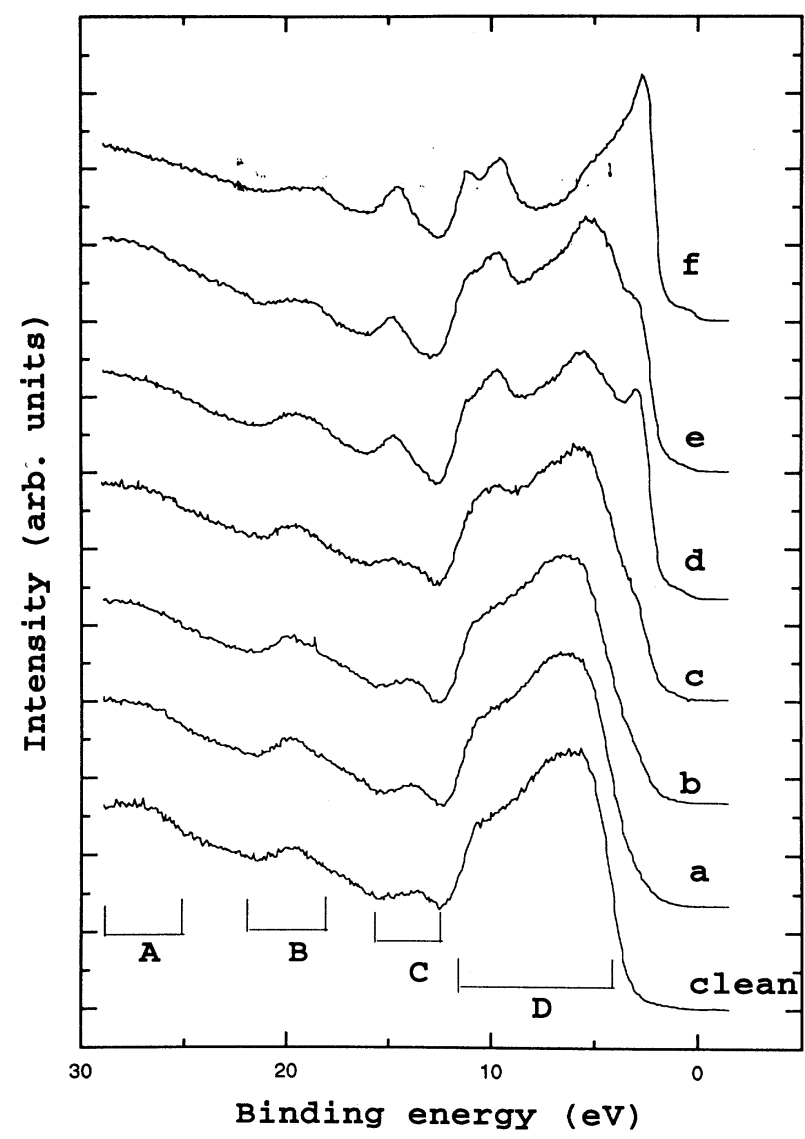

FIG. 7. Valence bands measured at 70-eV photon energy (except clean PET, $75 \mathrm{eV})$ with increasing copper coverage $(0.33$, $0.66,1.3,3,5$, and $10 \AA \mathrm{Cu}$, increasing from $a$ to $f$ ). A coverage of one $\mathrm{Cu}$ atom per PET unit corresponds to $0.31 \AA$. Peaks are labeled $A, B, C$, and $D$, in agreement with the corresponding peaks of clean PET. Peak $D$ stands for peaks $D, E$, and $F$ from Fig. 6.

noticed: the intensity of the highest occupied band $(F)$ located at around $3.5 \mathrm{eV}$ below the Fermi level which was assigned to $2 \pi$ benzene electrons increases noticeably with increasing $\mathrm{Cu}$ coverage. This is mainly due to the additional intensity from the copper $3 d$ emission which is also located at $3 \mathrm{eV} .{ }^{46}$ The $E$ band due to oxygen lone pairs (O $2 p$ character) shifts towards the Fermi level upon increasing $\mathrm{Cu}$ coverage. This shift is due to a perturbation resulting from partial charge transfer from the $\mathrm{Cu}$ to the oxygens of the polymer. A band $\left(D_{1}\right)$ composed of two peaks also grows at $10-11 \mathrm{eV}$ below Fermi level. It superimposes itself on the $\pi_{\mathrm{C}=\mathrm{O}}$ electron band (Table I) already present in the valence curve of pure PET. Such a structure has been observed in the $\mathrm{CuO}$ valence band ${ }^{47}$ and it is widely discussed in the literature $\mathrm{e}^{45,48-52}$ as a result of a $3 d^{8}$-like final state. These two-hole states are usually identified for $\mathrm{CuO}$ by the appearance of three peaks in the VB spectrum located at 10.5 and $12.9 \mathrm{eV}$ with a third weak component located approximately at $16.6 \mathrm{eV}$ from the Fermi level. ${ }^{48,50,52}$ This identification 
from UPS and XPS (Ref. 50) has received further support from a resonant photoemission study. ${ }^{52}$ In our case, $\mathrm{Cu}$ grown on PET seems to show such structures (at 10, 12, and $16 \mathrm{eV}$ ) for coverages over $4.2 \times 10^{14} \mathrm{Cu}$ atoms $/ \mathrm{cm}^{2}$. Hence we attribute these bands to the formation of $\mathrm{Cu}-$ $\mathrm{O}-\mathrm{C}$ complexes that appear as reaction products of $\mathrm{Cu} / \mathrm{PET}$ interface reaction. Furthermore, Davis ${ }^{49}$ has shown that, to a first approximation, only singlet final states are allowed to resonate in $\mathrm{CuO}$ when the photon energy crosses the $\mathrm{Cu} 3 p$ photoionization threshold. It has been confirmed using a somewhat more detailed mod$\mathrm{el}^{52}$ that most of the resonance occurs on these singlet states, primarily in the $3 d^{8}$ peaks $(10-12 \mathrm{eV}$ below Fermi level). We have also observed the $3 d^{8}$ peak enhancement around 10 and $12 \mathrm{eV}$ binding energy for a photon energy of $75 \mathrm{eV}$ (Fig. 8). This is in agreement with the existence of the $3 d^{8}$ character and thus the $\mathrm{Cu}-\mathrm{O}-\mathrm{C}$ polymer complex is confirmed.

\section{Analysis by XPS}

$\mathrm{Cu} / \mathrm{PET}$ interface growth at $300 \mathrm{~K}$. In Figs. 9-11, we show the XPS data for $\mathrm{C} 1 s, \mathrm{O} 1 s$, and $\mathrm{Cu} 2 p$ core levels to reveal the evolution of $\mathrm{Cu} / \mathrm{PET}$ interface at different $\mathrm{Cu}$ coverages. The spectra have been normalized to constant height in order to emphasize the chemical changes

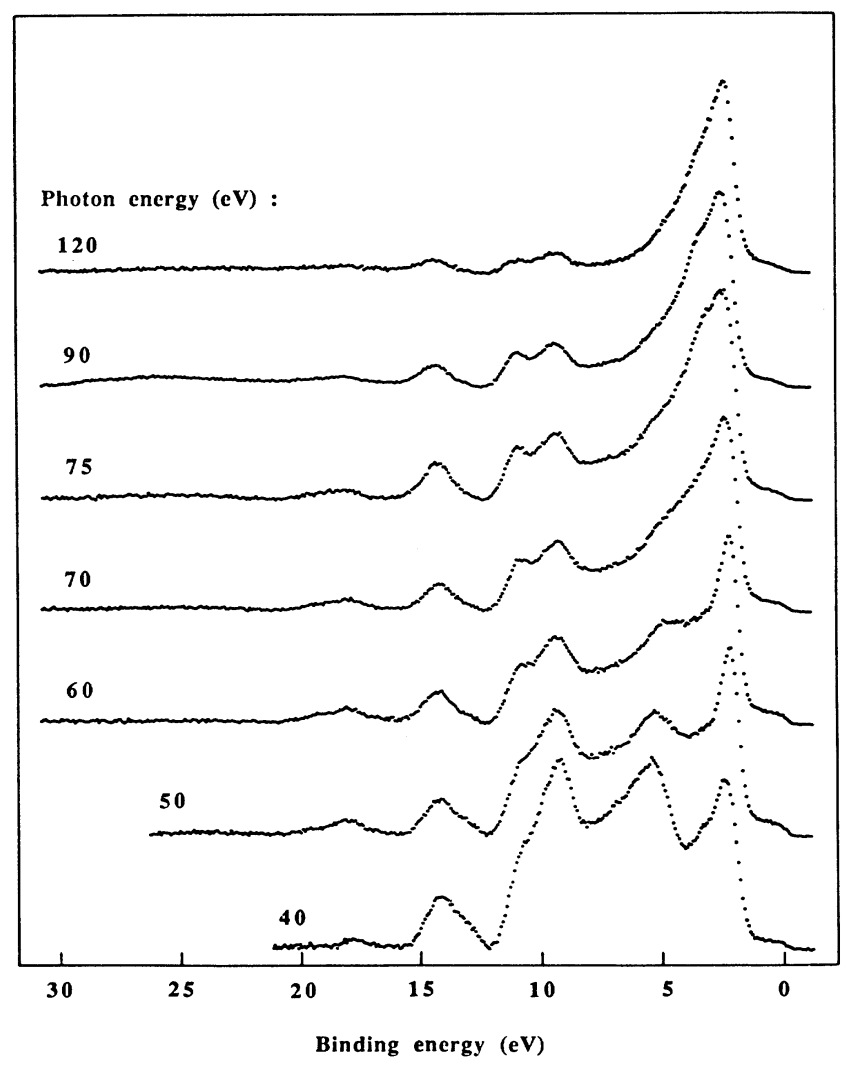

FIG. 8. Valence band measured at different photon energies, and in particular around the $\mathrm{Cu} 3 p-3 d$ Fano resonance. All spectra have been recorded for a coverage of $10 \AA \mathrm{Cu}$ $\left(5.9 \times 10^{15}\right.$ atoms $\left./ \mathrm{cm}^{2}\right)$.

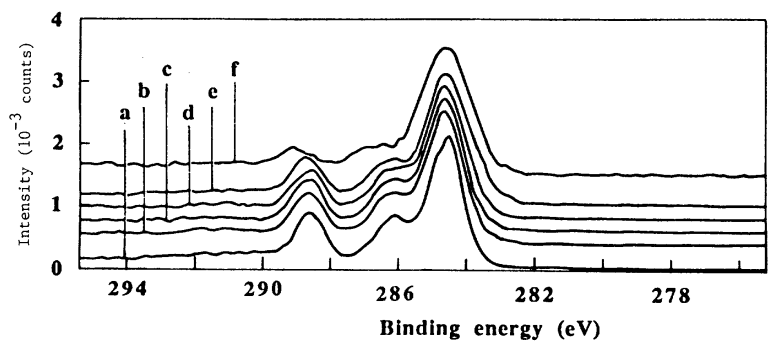

FIG. 9. C $1 s$ core level, measured for increasing coverages, corresponding to curves $a$ to $f$.

occurring at different metallization steps. Up to coverages of $6 \times 10^{15}$ atoms $/ \mathrm{cm}^{2}(10.3 \AA \mathrm{Cu})$ the carbonyl emission $(288.9 \mathrm{eV})$ intensity is seen from Fig. 9 to decrease. Similarly the intensity of the carbon $(\mathrm{O}-\mathrm{C})$ in the ether group $(286.6 \mathrm{eV})$ is also reduced, but to a lesser extent. Although the total intensity of the C $1 s$ emission is decreased, due essentially to the screening effect of the metallic layer, no further chemical shifts were apparent from the $\mathrm{C} 1 s$ spectra. In the case of $\mathrm{Ti}$ and $\mathrm{Cr}$ deposited on PI, the formation of a carbide is pointed out by the appearance of a peak at lower binding energy around 283 eV. ${ }^{13}$ The weak shakeup structure $\left(\pi^{*} \leftarrow \pi\right)$ at $290.5 \mathrm{eV}$ remains unperturbed even for coverages as high as $2.6 \times 10^{15}$ atoms $/ \mathrm{cm}^{2}(2.4 \AA \mathrm{Cu})$. This indicates that the chemical interaction between copper and PET benzene $\pi$ electrons is weak if not completely absent.

The $\mathrm{O} 1 \mathrm{~s}$ spectrum of Fig. 10 exhibits a peak on the low binding-energy side for coverages equivalent to more than one $\mathrm{Cu}$ atom per PET monomer. This component accounts for oxygen atoms that are bonded to the $\mathrm{Cu}$ atoms $(\mathrm{Cu}-\mathrm{O}-\mathrm{C}$ complex). The existence of a corresponding $\mathrm{Cu} 2 p$ peak at binding energy higher than the $\mathrm{Cu} 2 p$ metallic peak (low coverage) in Fig. 11 is also in agreement with the chemical binding of copper on the oxygen of the PET polymer, since its position $(933.2 \mathrm{eV})$ fits the value reported for $\mathrm{Cu} 2 p_{3 / 2}$ in CuO. ${ }^{50}$ Furthermore, the $[\mathrm{O}] /[\mathrm{C}]$ atomic ratio in PET should remain constant for different $\mathrm{Cu}$ thicknesses, since there is no loss in polymer material during interface growth. But according to Fig. 12, the atomic $[\mathrm{O}] /[\mathrm{C}]$ ratio decreases drastically for $\mathrm{Cu}$ coverages above $5.9 \times 10^{14}$ atoms $/ \mathrm{cm}^{2}(0.5 \AA)$. That is to say that the intensity of the oxygen decreases more rapidly than the carbon intensity does. Again, this observation favors the preferential $\mathrm{Cu}$ attack on the oxygenated functionality of PET. In the case of such a thin overlayer, the smaller mean free path of the $\mathrm{O} 1 \mathrm{~s}$ photoelectrons (compared to the $\mathrm{C} 1 s$ ones) cannot be the reason for this decrease.

Figure 13 shows the decrease of $[\mathrm{O}] /[\mathrm{Cu}]$ ratio versus $\mathrm{Cu}$ thickness. The exponential shape of the curve is typical for islandlike growth. ${ }^{53-55}$ It also shows a break point at a coverage around $6.9 \times 10^{14} \mathrm{Cu}$ atoms $/ \mathrm{cm}^{2}$. This coverage corresponds to one $\mathrm{Cu}$ atom per oxygen atom of the PET unit cell (four oxygens in PET). From all the results presented, it seems that the $\mathrm{Cu}$ atoms cluster around the oxygen sites of the polymer substrate. 


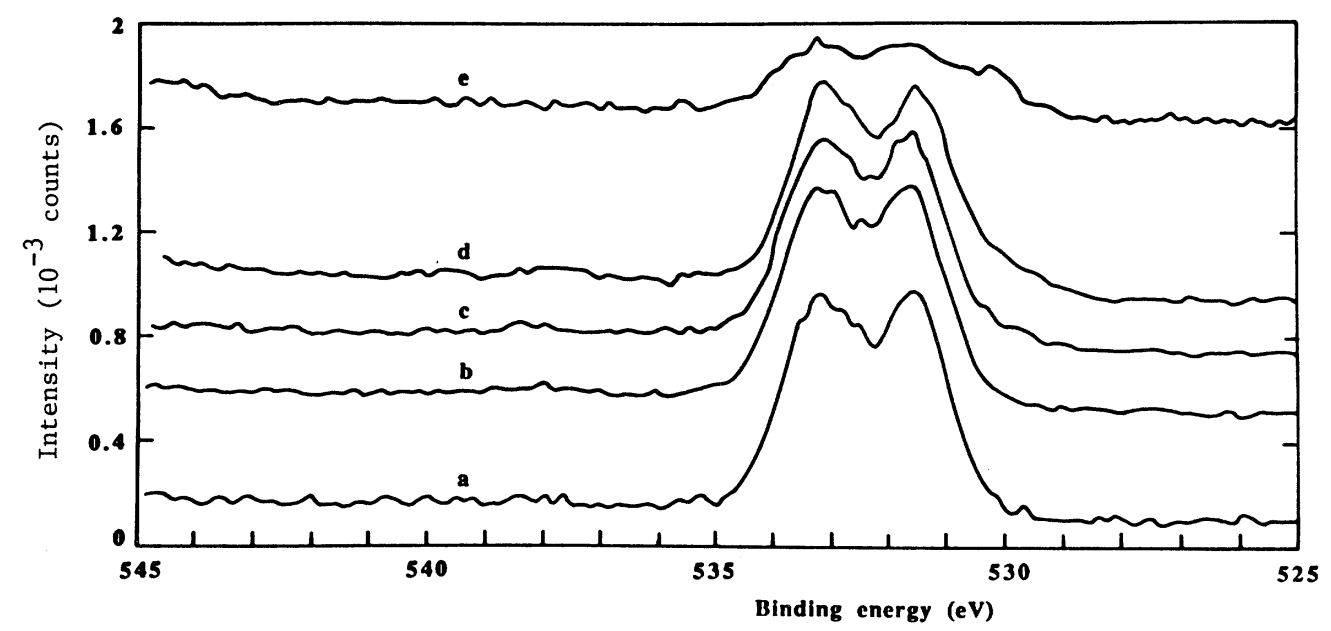

FIG. 10. O $1 s$ core level, measured for the same coverages as in Fig. 9.

Behavior of the CU/PET interface under heat treatment at $450 \mathrm{~K}$. In another experiment after growing $1.2 \AA \mathrm{Cu}$ on a PET sample, it was gently heated up to $450 \mathrm{~K}$ and maintained at this temperature for more than $24 \mathrm{~h}$ in the analysis chamber. Core-level spectra of $\mathrm{C} 1 s, \mathrm{O} 1 \mathrm{~s}$, and $\mathrm{Cu} 2 p$ were recorded every $15 \mathrm{~min}$ during heating. The most striking effect is the decay of the $\mathrm{Cu} 2 p$ intensity (see Fig. 14). This may be due to diffusion of the metallic $\mathrm{Cu}$ in the polymer material as has been reported by other authors. ${ }^{6,19,56-59}$ However, after $3 \mathrm{~h}$, the diffusion reaches a plateau. The remaining copper (within XPS probing depth) seems to be oxidized as it gives rise to a $\mathrm{Cu} 2 p$ signal located at a higher binding energy than the metallic peak $(933.2 \mathrm{eV})$.

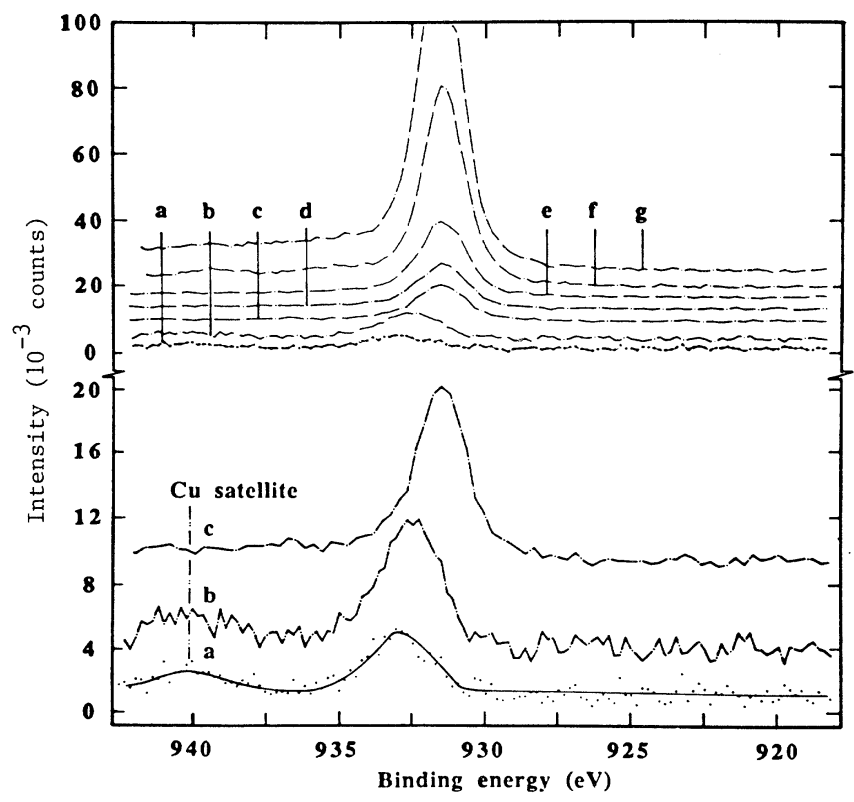

FIG. 11. Cu $2 p$ core level, measured for the same coverages as in Fig. 9. The three first spectra are plotted with an expanded $y$ scale at the bottom.

\section{SUMMARY AND CONCLUSIONS}

A detailed assignment of the valence-band structure of PET was obtained from a theoretical VEH calculation. A very good agreement between the measured EDC's and the calculated density of states is demonstrated. This allowed us to go further in following the modification of the PET valence band upon metallization.

The results of the SR photoemission study show interesting behavior during the early stage of $\mathrm{Cu}$ growth on PET: $\mathrm{Cu}$ atoms interact with oxygenated functionalities and form $\mathrm{Cu}-\mathrm{O}-\mathrm{C}$ polymer complexes at the interface. The chemical interactions involved in the formation of

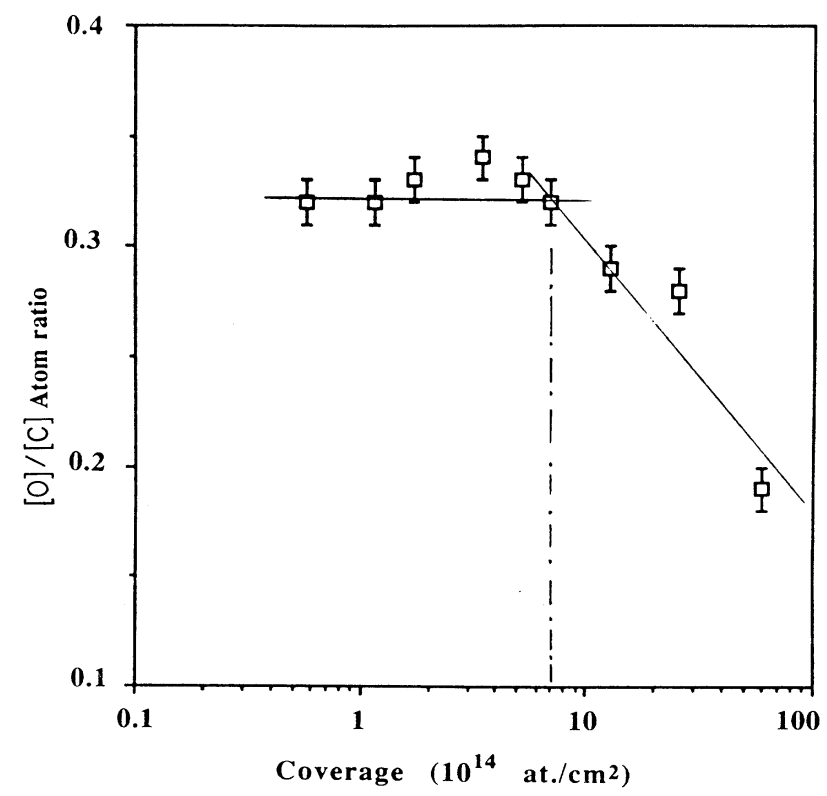

FIG. 12. Ratio of oxygen and carbon atomic percentage vs $\mathrm{Cu}$ coverage, derived from XPS core-level intensities. 


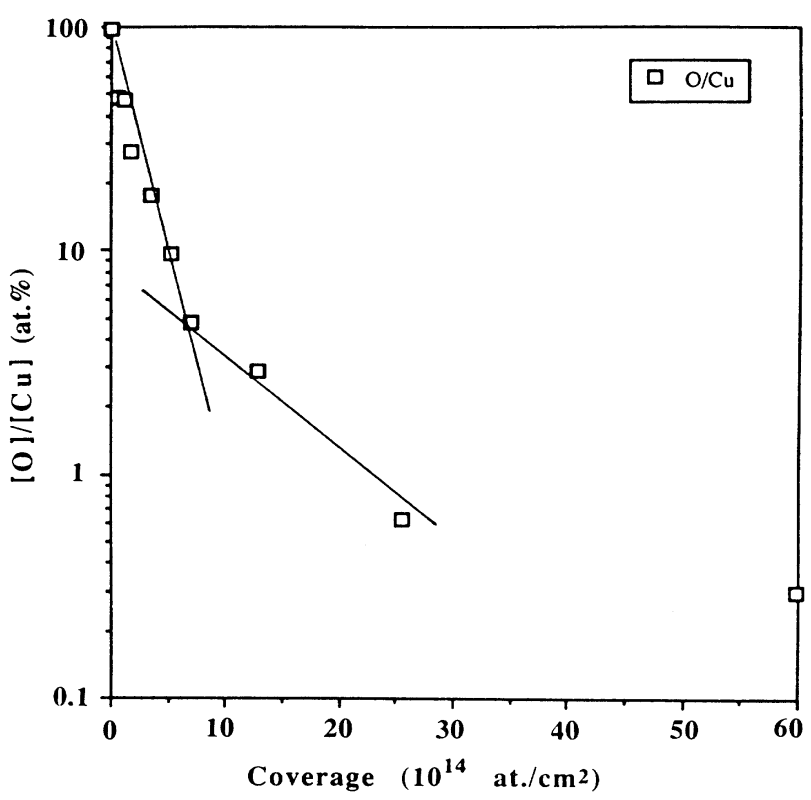

FIG. 13. Ratio of oxygen and copper atomic percentages vs $\mathrm{Cu}$ coverage, derived from XPS core-level intensities.

such an interface appear to be weak compared to other metals on PET. This is essentially due to the fact that copper has a full complement of $d$ electrons and this determines the low reactivity. It also appears that the metallic state is achieved at rather low coverages. At higher coverages, $\mathrm{Cu}$ atoms bond to the $\mathrm{Cu}$ atoms in the $\mathrm{Cu}-\mathrm{O}-\mathrm{C}$ polymer complex to build clusters.

\section{ACKNOWLEDGMENTS}

This work was partly supported by the DGICYT Project No. PS88-0112 and by the German Federal Minister

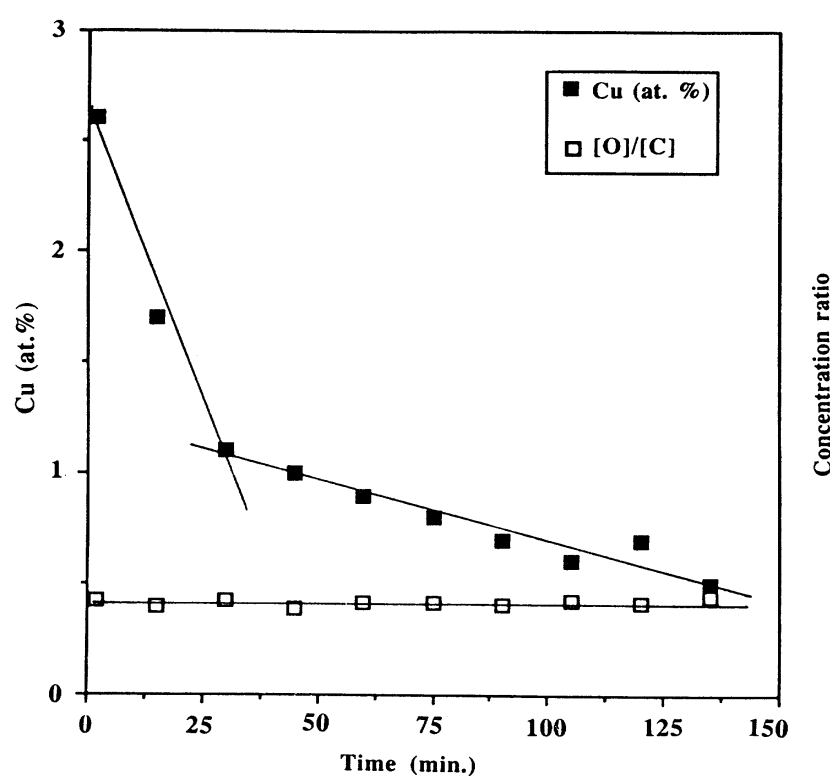

FIG. 14. $\mathrm{Cu}$ atomic percentage and ratio of oxygen and carbon atomic percentages as a function of time, at constant temperature $(450 \mathrm{~K})$, starting from a Cu overlayer of $1.2 \AA$.

for Research and Technology (BMFT), under Grant No. 05490 CAB. We thank the University of Mons Computer Center for the use of the CCI facility and SPPS "Programme d'Impulsion en Technologie de l'Information" (Contract No. IT/SC/22). One of us (J.G.) is supported by the National Fund for Scientific Research (Belgium). E.O. is grateful to the University of Mons for its hospitality and financial support and is also indebted to the Conselleria de Cultura, Educacion y Ciencia de la Generalitat Valenciana for a grant, and M.C. is supported by the EEC Brite program (Grant No. RI 1B 0178).
*Present address: Laborlux Société Anonyme, Boîte Postale 349, L-4004 Esch-sur-Alzette, Luxembourg.

${ }^{\dagger}$ Permanent address: Universidad de Valencia, Departamento de Química-Física, Dr. Moliner 50, E-46100 Burjassot, Valencia, Spain.

${ }^{1}$ See, for example, Proceedings of the Symposium on Metallized Plastics: Fundamental and Applied Aspects, edited by K. L. Mittal and J. R. Susko (Plenum, New York, 1990).

${ }^{2}$ M. C. Burrell, P. J. Codella, J. A. Fontana, J. J. Chera, and M. D. McConnell, J. Vac. Sci. Technol. A 7, 55 (1989).

${ }^{3}$ See Polyimides, edited by K. L. Mittal (Plenum, New York, 1984), Vols. I and II.

${ }^{4}$ N. J. Chou and C. H. Tang, J. Vac. Sci. Technol. A 2, 751 (1984).

${ }^{5}$ K. L. Mittal, J. Vac. Sci. Technol. 13, 19 (1976).

${ }^{6}$ F. K. Le Goues, B. D. Silverman, and P. S. Ho, J. Vac. Sci. Technol. A 6, 4 (1988).

${ }^{7}$ L. J. Atanasoska, S. G. Anderson, H. M. Meyer III, Z. Lin, and J. H. Weaver, J. Vac. Sci. Technol. A 5, 6 (1987).
${ }^{8}$ P. S. Ho, P. O. Hahn, J. W. Bartha, G. W. Rubloff, F. K. Le Goues, and B. D. Silverman, J. Vac. Sci. Technol. A 3, 3 (1985).

${ }^{9}$ J. M. Burkstrand, Phys. Rev. B 20, 4853 (1979).

${ }^{10}$ N. J. Dinardo, J. E. Demuth, and T. C. Clarke, J. Vac. Sci. Technol. A 4, 1050 (1986).

${ }^{11}$ J. J. Pireaux, M. Vermeersch, C. Grégoire, T. C. Clarke, and R. Caudano, J. Chem. Phys. 88, 5 (1988).

${ }^{12}$ Y. Novis, M. Chtaib, and R. Caudano (unpublished).

13J. L. Jordan, C. A. Kovac, J. F. Moren, and P. A. Pollak, Phys. Rev. B 36, 1369 (1987).

${ }^{14}$ R. Haight, R. C. White, B. D. Silverman, and P. S. Ho, J. Vac. Sci. Technol. A 6, 2188 (1988).

${ }^{15}$ S. P. Kowalczyk and J. L. Jordan-Sweet, Chem. Mater. 1, 592 (1989).

${ }^{16}$ P. N. Sanda, J. W. Bartha, J. G. Clabes, J. L. Jordan, C. Feger, B. D. Silverman, and P. S. Ho, J. Vac. Sci. Technol. A 4, 3 (1986).

${ }^{17}$ R. C. White, R. A. Haight, B. D. Silverman, and P. S. Ho, 
Appl. Phys. Lett. 51, 7 (1987).

${ }^{18}$ P. S. Ho, B. D. Silverman, R. A. Haight, R. C. White, P. N. Sanda, and A. R. Rossi, IBM J. Res. Dev. 32, 5 (1988).

${ }^{19}$ R. M. Tromp, F. K. Le Goues, and P. S. Ho, J. Vac. Sci. Technol. A 3, 782 (1985).

${ }^{20}$ P. O. Hahn, G. W. Rubloff, J. W. Bartha, F. K. Le Goues, and P. S. Ho, Symp. Proc. Electron. Mater. Packaging, Mater. Res. Soc. Boston 40, 251 (1985).

21J. L. Brédas, R. R. Chance, R. Silbey, G. Nicolas, and Ph. Durand, J. Chem. Phys. 77, 371 (1982); J. L. Brédas, R. R. Chance, R. H. Baughman, and R. Silbey, ibid. 78, 5656 (1983).

22J. L. Brédas, Chem. Phys. Lett. 115, 119 (1985); J. L. Brédas and W. R. Salaneck, J. Chem. Phys. 85, 2219 (1986).

${ }^{23}$ C. R. Wu, J. O. Nilsson, O. Inganä, W. R. Salaneck, J. R. Osterholm, and J. L. Brédas, Synth. Met. 21, 197 (1987); R. Lazzaroni, J. Riga, J. Verbist, J. L. Brédas, and F. Wudl, J. Chem. Phys. 88, 4257 (1988).

${ }^{24}$ (a) E. Ortí, S. Stafström, and J. L. Brédas, Chem. Phys. Lett. 164, 240 (1989); (b) E. Ortí, J. L. Brédas, J. J. Pireaux, and N. Ishihara, J. Electron. Spectrosc. Relat. Phenom. 52, 551 (1990).

${ }^{25}$ S. P. Kowalczyk, S. Stafström, J. L. Brédas, W. R. Salaneck, and J. L. Jordan-Sweet, Phys. Rev. B 41, 1645 (1990).

${ }^{26}$ R. Lazzaroni, N. Sato, W. R. Salaneck, M. C. Dos Santos, J. L. Brédas, B. Tooze, and D. T. Clark, Chem. Phys. Lett. 175, 175 (1990).

${ }^{27}$ R. L. Johnson and J. Reichardt, Nucl. Instrum. Methods 208, 791 (1983).

${ }^{28}$ C. R. Fisher and J. L. Whitten, Phys. Rev. B 40, 5745 (1982).

${ }^{29}$ R. P. Daubeny, C. W. Bunn, and C. J. Brown, Proc. R. Soc. London Ser. A 226, 531 (1954).

${ }^{30}$ G. Nicolas and Ph. Durand, J. Chem. Phys. 70, 2020 (1979); 72, 453 (1980).

${ }^{31}$ J. M. André, L. A. Burke, J. Delhalle, G. Nicolas, and Ph. Durand, Int. J. Quantum Chem. Symp. 13, 283 (1979).

${ }^{32}$ J. L. Brédas, R. R. Chance, R. Silbey, G. Nicolas, and Ph. Durand, J. Chem. Phys. 75, 255 (1981).

${ }^{33}$ B. Thémans, J. M. André, and J. L. Brédas, Mol. Cryst. Liq. Cryst. 118, 121 (1985).

${ }^{34}$ J. Delhalle and S. Delhalle, Int. J. Quantum Chem. 11, 349 (1977).

${ }^{35}$ U. Gelius, in Electron Spectroscopy, edited by D. A. Shirley (North-Holland, Amsterdam, 1972), p. 311.
36J. Delhalle, S. Delhalle, and J. M. André, Chem. Phys. Lett. 34, 430 (1975).

${ }^{37}$ M. J. Dewar, E. G. Zoebish, E. F. Healy, and J. J. P. Stewart, J. Am. Chem. Soc. 107, 3902 (1985).

${ }^{38}$ M. Bailey, Acta Crystallogr. 2, 120 (1949).

${ }^{39}$ J. J. Pireaux, J. Riga, R. Caudano, and J. Verbist (unpublished).

${ }^{40}$ D. T. Clark, CRC Crit. Rev. Solid State Mater. Sci. 1, 1 (1978).

${ }^{41}$ D. W. Dwight, J. E. McGrath, and J. P. Wightman, J. Polymer Sci.: Appl. Polymer Symp. 34, 35 (1978).

42J. Riga, J. J. Pireaux, R. Caudano, and J. Verbist, Phys. Scr. 16, 346 (1977).

${ }^{43}$ L. Klasinc, Int. J. Quantum Chem. Quantum Biol. Symp. 5, 373 (1978).

${ }^{44}$ W. Ranke and H. J. Kur, Phys. Rev. B 39, 1595 (1989).

${ }^{45}$ H. Eskes and G. A. Sawatzky, Phys. Rev. B 44, 9656 (1991).

${ }^{46}$ M. Grioni, M. T. Czyzyk, F. M. F. De Groot, J. C. Fuggle, and B. E. Watts, Phys. Rev. B 39, 4886 (1989).

${ }^{47}$ M. R. Thuler, R. L. Benbow, and Z. Hurych, Phys. Rev. B 26, 669 (1982).

${ }^{48}$ L. C. Davis, J. Appl. Phys. 59, 25 (1985).

${ }^{49}$ L. C. Davis, Phys. Rev. B 25, 2912 (1982).

${ }^{50}$ J. Ghijsen, L. H. Tjeng, J. van Elp, H. Eskes, J. Westerink, G. A. Sawatzky, and M. T. Czyzyk, Phys. Rev. B 38, 11322 (1988).

${ }^{51}$ L. C. Davis, Phys. Scr. T17, 13 (1987).

${ }^{52}$ J. Ghijsen, L. H. Tjeng, H. Eskes, G. A. Sawatzky, and R. L. Johnson, Phys. Rev. B 42, 2268 (1990).

53J. A. Venables, G. D. T. Spiller, and M. Hanbucken, Rep. Prog. Phys. 47, 399 (1984).

${ }^{54}$ R. A. Butera and C. A. Hollingsworth, Phys. Rev. B 37, 10487 (1988).

${ }^{55}$ F. Boscherini, Y. Shapira, C. Capasso, C. Aldo, M. del Giudia, and J. H. Weaver, Phys. Rev. B 35, 9580 (1987).

${ }^{56}$ S. P. Kowalczyk, Y. H. Kim, and G. F. Walker, Appl. Phys. Lett. 52, 375 (1988).

${ }^{57}$ M. Grunze and R. N. Lamb, Chem. Phys. Lett. 133, 283 (1987).

${ }^{58}$ K. Shanker and J. R. McDonald, J. Vac. Sci. Technol. A 5, 2894 (1987).

${ }^{59}$ D. Y. Shih, J. Paraszczak, N. Klymko, R. Flitsch, S. Nunes, J. Lewis, C. Vang, J. Cataldo, R. McGoney, W. Graham, R. Serino, and E. Galligan, J. Vac. Sci. Technol. A 7, 3 (1989). 